\title{
BIOFILM FORMATION OF ACHROMOBACTER XYLOSOXIDANS ON CONTACT LENS
}

\author{
Neda Konstantinović ${ }^{1}$, IVANa ĆIRKOViĆ ${ }^{1}$, SlobodanKa ĐukiĆ $^{1}$, \\ VESNA MARIĆ ${ }^{2}$ and DRAGANA D. BOŽIĆ ${ }^{3}$ \\ ${ }^{1}$ Institute of Microbiology and Immunology, Faculty of Medicine, University of Belgrade, \\ Belgrade, Serbia \\ ${ }^{2}$ Clinic of Eye Diseases, Clinical Center of Serbia, Belgrade, Serbia \\ ${ }^{3}$ Department of Microbiology and Immunology, Faculty of Pharmacy, University of \\ Belgrade, Belgrade, Serbia
}

(Received: 23 July 2016; accepted: 19 November 2016)

\begin{abstract}
Achromobacter spp. may contaminate lenses, lens cases, and contact lens solutions and cause ocular infections. The aim of this study was to investigate the possibility of isolated strain of Achromobacter xylosoxidans to form biofilm on the surface of soft contact lenses (CL), to quantify the production of the formed biofilm, and compare it with the reference strains (Pseudomonas aeruginosa, Staphylococcus aureus, and Haemophilus influenzae). Bacterial strain isolated from one contact lens case was identified as A.xylosoxidans using Vitek2 Automated System. Biofilm forming capacity of isolated strain of A.xylosoxidans and reference strains of $P$. aeruginosa, $S$. aureus, and $H$. influenzae on soft CL were analyzed by commonly used microtitre plate method. Our results showed that isolated strain of $A$. xylosoxidans was capable to form biofilm on the surface of soft contact lens. A.xylosoxidans was strong biofilm producer while all examined reference strains were moderate biofilm producers. A.xylosoxidans appears to be superior biofilm producer on soft CL compared to reference strains.
\end{abstract}

Keywords: Achromobacter xylosoxidans, biofilm, contact lens

\section{Introduction}

Biofilms are composed of bacterial cells attached to biotic or abiotic surfaces and encased in a complex, self-secreted polymeric matrix. Bacteria in a biofilm differ from planktonic cells, in having an increased resistance to antimicrobials and the host immune defence [1].

*Corresponding author; E-mail: neda.konstantinovic@gmail.com 
The presence of bacterial biofilms has been demonstrated on many medical devices such as urinary catheters, intrauterine devices, ventricular assist devices, neurosurgical ventricular shunts, prosthetic heart valves, intravascular catheters, coronary stents, prosthetic joint, cochlear implants, intraocular and contact lenses (CL) [1,2]. Since CL are increasingly being used, they became one of the main predisposing risk factors for infectious keratitis [3, 4]. Integrity of the epithelial surface of cornea is compromised by the interactions of lens and ocular surface, which increases the ability of microbes to adhere and cause an infection in healthy host [5]. Also, the presence of biofilm on the contact lens may increase potential pathogenicity of bacteria, by prolonging their retention time at the ocular surface [6]. It is documented that biofilm present on lenses or lens cases shows enhanced resistance to the antimicrobial activities of contact lens solutions [7].

Pseudomonas aeruginosa is documented as the most common causative agent of infections related to contact lens wear, and Serratia marcescens, Staphylococcus aureus, Acanthamoeba spp., and Fusarium spp. as following major causative pathogens [8]. The ability of $P$. aeruginosa, S. marcescens, and $S$. aureus to form biofilms on CL is well documented in the literature [2, 7].

Achromobacter xylosoxidans is a closely related bacterium to Pseudomonas spp. - aerobic, non-glucose-fermenting, Gram-negative rod [9]. Thus, its role as an important pathogen may be underestimated, but recent studies showed that Achromobacter spp. may contaminate lenses, lens cases, and contact lens solutions and subsequently cause corneal infiltrative events (CIEs) [8, 10-12]. Based on a literature, there are 12 reported cases of A.xylosoxidans keratitis [12]. Infections due to A.xylosoxidans, as a water pathogen, are associated with humidifiers and disinfectants in hospitals, but contaminated hands can also spread the bacterium to the CL, lens solution, and lens case $[8,12,13]$. Also, a study using scanning electron microscopy (SEM) showed that Achromobacter spp. were able to form biofilms on the surface of CL from patients with microbial keratitis [8]. To the best of our knowledge, there is no data describing the occurrence of A.xylosoxidans as a causative agent of contact lens-associated keratitis as well as a contaminant of contact lens cases in Serbia.

The aim of this study was to investigate the possibility of isolated strain of A. xylosoxidans from contact lens case to form biofilm on the surface of soft contact lens, to quantify the production of the formed biofilm, and compare it with the reference strains (P. aeruginosa, S. aureus, and Haemophilus influenzae). 


\section{Materials and Methods}

\section{Bacterial strain}

Samples from 71 contact lens cases used by asymptomatic contact lens wearers were streaked onto Columbia agar plate (Torlak, Serbia) containing $5 \%$ sheep blood and MacConkey agar plate (HiMedia, India). After incubation at $37{ }^{\circ} \mathrm{C}$ for $24 \mathrm{~h}$, the colonies were identified by automated Vitek2 System (bioMérieux, France) using GN card. The strain from one contact lens case was identified as A. xylosoxidans.

\section{Biofilm assay}

In order to detect, quantify, and compare the production of biofilm on soft CL (Air Optix, Alcon, USA) by isolated strain of $A$. xylosoxidans, reference strains $P$. aeruginosa ATCC 27853, S. aureus ATCC 29213, and $H$. influenzae ATCC 49766 were also analyzed. Bacterial suspensions of tested strains were prepared in sterile saline and adjusted to the density of $0.5 \mathrm{McF}$ arland standard.

CL were placed in separate wells of 24-well microtitre plates (Sarstedt) with $1,800 \mu \mathrm{L}$ of tryptic soy broth (bioMérieux) supplemented with additional $1 \%$ glucose. Two hundred microliters of previously prepared bacterial suspension of analyzed strains were added to each well. Negative control for each plate represented only the medium with and without CL. After $24 \mathrm{~h}$ of incubation at $35^{\circ} \mathrm{C}$ in aerobic conditions, plates with $\mathrm{CL}$ were decanted and rinsed gently three times with $2,000 \mu \mathrm{L}$ of sterile phosphate-buffered saline $(\mathrm{pH} 7.2)$ in order to remove planktonic bacteria. After air drying, plates with $\mathrm{CL}$ were fixed with $2,000 \mu \mathrm{L}$ methanol per well for $20 \mathrm{~min}$, dried and stained with $2,000 \mu \mathrm{L}$ per well of $2 \%$ crystal violet (bioMérieux) for $15 \mathrm{~min}$. Unbounded dye was rinsed with water. After air drying, CL were transferred into new 24-well microtitre plates and dye bound to biofilm formed on CL was released with $2,000 \mu \mathrm{L}$ of $96 \%$ ethanol per well for $20 \mathrm{~min}$ at room temperature, with gentle tapping. Extracted dye was transferred to 96 -well microtitre plates $(150 \mu \mathrm{L}$ per well) and optical density (OD) was measured at $570 \mathrm{~nm}$ using a microtitre plate reader (ICN Flow Titertek Multiscan Plus, Germany). The results were calculated according to Stepanović et al. [14]. Each assay was repeated three times on three consecutive days. OD value of negative control (CL cultivated in medium without bacteria) was subtracted from measured OD values of all tested strains and mean OD values 
from three experiments were calculated. To calculate the category of biofilm production, the cut-off optical density (ODc) was determined as three standard deviations above the mean OD of the negative control. According to the obtained results all tested strains were divided into four groups: $\mathrm{OD} \leq \mathrm{ODc}$ - category 0 (no biofilm producer); ODc $<\mathrm{OD} \leq 2 \times \mathrm{ODc}$ - category 1 (weak biofilm producer, + ); $2 \times \mathrm{ODc}<\mathrm{OD} \leq 4 \times \mathrm{ODc}-$ category 2 (moderate biofilm producer, ++ ); $4 \times \mathrm{ODc}<$ OD - category 3 (strong biofilm producer, +++ ).

\section{Results}

Bacterial strain isolated from one of 71 contact lens cases was identified as A. xylosoxidans. We examined if isolated strain of $A$. xylosoxidans was capable to produce biofilm on soft CL. Quantification of biofilm production on soft CL by isolated strain of A.xylosoxidans compared with reference strains is presented in Table I and Figure 1.

\section{Discussion}

We investigated the possibility of isolated strain of A.xylosoxidans from contact lens case to form biofilm on the surface of soft CL. We found that the examined strain was able to produce biofilm on contact lens.

Kilvington et al. [11] showed the ability of Achromobacter spp. to survive within dry storage cases and assumed it was related to protection gained from biofilm formation.

Study using culture-independent methods found that Achromobacter spp. was predominant bacterium in patients with contact lens-related corneal disease, with occurrence of $76 \%$ of lens cases. This outcome was in part explained by the

Table I. Category of biofilm production by isolated and reference strains

\begin{tabular}{lc}
\hline Strains & Category \\
\hline Achromobacter xylosoxidans & +++ \\
Pseudomonas aeruginosa ATCC 27853 & ++ \\
Staphylococcus aureus ATCC 29213 & ++ \\
Haemophilus influenzae ATCC 49766 & ++ \\
Sterile lens & 0 \\
\hline
\end{tabular}

Note: +++ , category 3 - strong biofilm producer; ++ , category $2-$ moderate biofilm producer; 0 , category $0-$ no biofilm producer. 


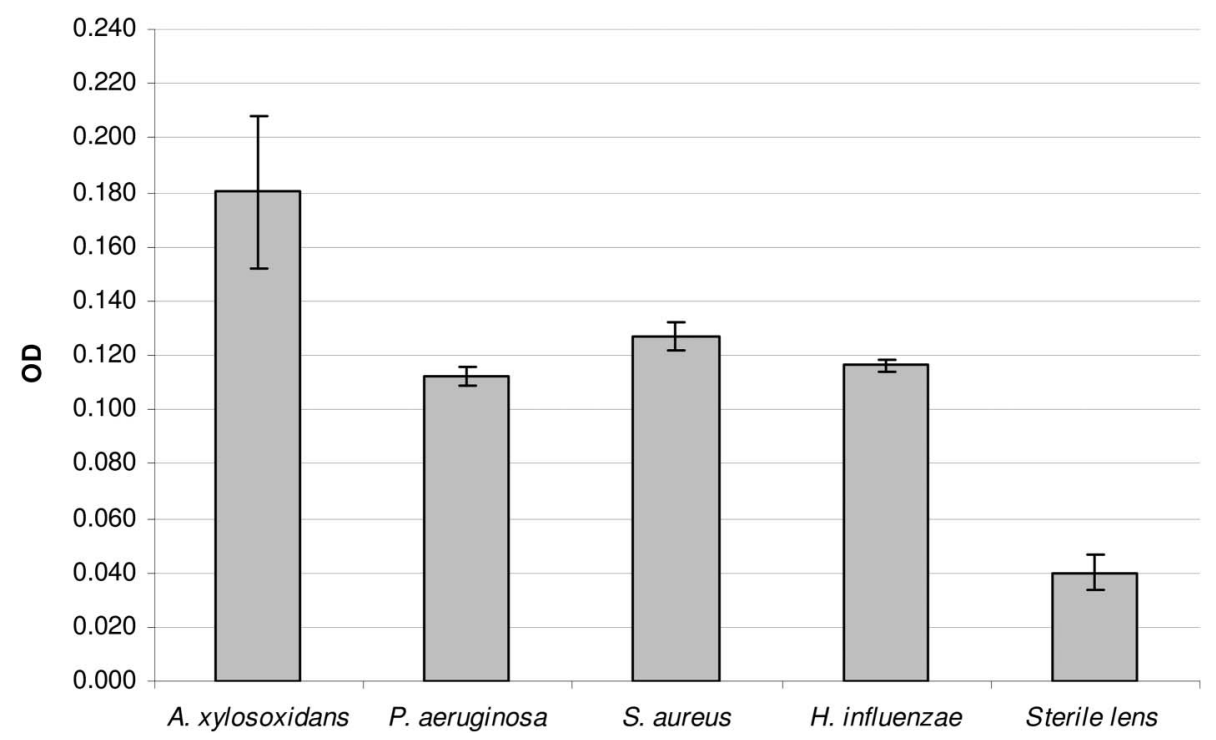

Figure 1. Biofilm production of analyzed strains on soft contact lenses. OD, optical density

ability of Achromobacter to form biofilms on the surface of CL, which was confirmed by SEM analysis [8].

Some studies showed that Achromobacter spp. can form biofilm on surfaces other than CL, such as central venous catheters and urinary catheters $[15,16]$. The presence of biofilms in sputum from cystic fibrosis (CF) patients infected with A. xylosoxidans was revealed in one study. This study showed that bacterial cells in A. xylosoxidans biofilms are located very close to each other, unlike biofilms of $P$. aeruginosa, where rich extracellular matrix separates bacterial cells [17].

Our study showed that isolated A.xylosoxidans strain was strong biofilm producer, while reference strains were moderate biofilm producers. Trancassini et al. [18] showed the ability of A. xylosoxidans isolated from samples of CF and non-CF patients to form biofilms on abiotic surfaces. According to this study, the majority of isolated strains $(57.9 \%)$ were strong biofilm producers, while $26.3 \%$ strains were moderate, and only $12.3 \%$ strains were weak biofilm producers [18].

According to Reddy et al. [13] penetrating keratoplasty and topical steroid use are the main risk factors in A. xylosoxidans ocular infections. However, recent study where 8 out of 28 patients with A.xylosoxidans keratitis were contact lens wearers, implicates that contact lens wear may also be an important risk factor [19]. Three case reports of keratitis and one case report of conjunctivitis caused by A. xylosoxidans in healthy contact lens wearers were previously described, 
pointing out that this organism should be considered as potential pathogen in contact lens-related ocular infections [10, 12, 20].

A. xylosoxidans is often confused with other Gram-negative rods, which is the reason why A.xylosoxidans ocular infections are probably underreported [13]. Although A.xylosoxidans is very similar to Pseudomonas, it differs from Pseudomonas in being less virulent and having different antibiotic resistance profiles and clinical presentation $[8,19]$.

Since there are difficulties in identifying the causative organism in contact lens-related ocular infections, American Academy of Ophthalmology [21] recommended empiric administration of antibiotics for those infections with no causative organism identified. Their recommendations are fluoroquinolones or cefazolin/ tobramycin combination therapy. A study using culture-independent methods, mentioned above, also explained the prevalence of Achromobacter over Pseudomonas by the resistance of this organism to empirical antibiotics used in treatment of corneal infection [8].

A. xylosoxidans should be considered as a potential pathogen in patients showing Gram-negative bacilli on smear examination who have compromised ocular status and slowly progressive disease [13].

The international ISO 14729 and FDA 510(k) standards for adequate antimicrobial efficacy of contact lens multipurpose solutions are based only on tests which determine the efficacy against reference strains of planktonic bacteria and fungi ( $P$. aeuruginosa, S. aureus, S. marcescens, Fusarium solani, and Candida albicans) [22]. Antimicrobial activity against such strains does not guarantee efficacy against clinical isolates. In one study, Achromobacter spp. was isolated in the majority (61\%) of contact lens cases of contact lens wearers with CIEs, that all used the same multipurpose disinfecting solution (MPDS). High levels of contamination were explained by the resistance of isolated strains to the biocidal components of the used MPDS [11].

A study showing that bacterial biofilms formed on contact lens surfaces are more resistant to contact lens solutions than planktonic cells, pointed out the importance of incorporating tests for activity against biofilms and not only against planktonic cells [7]. Chang et al. [23] found that A.xylosoxidans biofilms were more resistant to the two common ophthalmic preservatives than biofilms of $P$. aeruginosa, and suggested the incorporation of A.xylosoxidans biofilm in antimicrobial efficacy tests which would improve safety of multiuse ophthalmic products.

In our study, we have shown that isolated strain of A.xylosoxidans was capable to form strong biofilm on the surface of soft CL, and that it appears to be superior biofilm producer relative to reference strains. 


\section{Acknowledgement}

This research was supported by the Ministry of Education, Science and Technological Development, Republic of Serbia (project no. ON175039).

\section{Conflict of Interest}

The authors declare no conflict of interest.

\section{References}

1. Donlan, R. M., Costerton, J. W.: Biofilms: Survival mechanisms of clinically relevant microorganisms. Clin Microbiol Rev 15, 167-193 (2002).

2. Bispo, P. J., Haas, W., Gilmore, M. S.: Biofilms in infections of the eye. Pathogens 4, 111-136 (2015).

3. Bourcier, T., Thomas, F., Borderie, V., Chaumeil, C., Laroche, L.: Bacterial keratitis: Predisposing factors, clinical and microbiological review of 300 cases. Br J Ophthalmol 87, 834-838 (2003).

4. Keay, L., Edwards, K., Naduvilath, T., Taylor, H. R., Snibson, G. R., Forde, K., Stapleton, F.: Microbial keratitis: Predisposing factors and morbidity. Ophthalmology 113, 109-116 (2006).

5. Robertson, D. M.: The effects of silicone hydrogel lens wear on the corneal epithelium and risk for microbial keratitis. Eye Contact Lens 39, 67-72 (2013).

6. McLaughlin-Borlace, L., Stapleton, F., Matheson, M., Dart, J. K.: Bacterial biofilm on contact lenses and lens storage cases in wearers with microbial keratitis. J Appl Microbiol 84, 827-838 (1998).

7. Szczotka-Flynn, L. B., Imamura, Y., Chandra, J., Yu, C., Mukherjee, P. K., Pearlman, E., Ghannoum, M. A.: Increased resistance of contact lens-related bacterial biofilms to antimicrobial activity of soft contact lens care solutions. Cornea 28, 918-926 (2009).

8. Wiley, L., Bridge, D. R., Wiley, L. A., Odom, J. V., Elliott, T., Olson, J. C.: Bacterial biofilm diversity in contact lens-related disease: Emerging role of Achromobacter, Stenotrophomonas, and Delftia. Invest Ophthalmol Vis Sci 53, 3896-3905 (2012).

9. Igra-Siegman, Y., Chmel, H., Cobbs, C.: Clinical and laboratory characteristics of Achromobacter xylosoxidans infection. J Clin Microbiol 11, 141-145 (1980).

10. Kiernan, D. F., Chin, E. K., Sclafani, L. A., Saidel, M. A.: Multiple drug-resistant Alcaligenes xylosoxidans keratitis in a sanitation worker. Eye Contact Lens 35, 212-214 (2009).

11. Kilvington, S., Shovlin, J., Nikolic, M.: Identification and susceptibility to multipurpose disinfectant solutions of bacteria isolated from contact lens storage cases of patients with corneal infiltrative events. Cont Lens Anterior Eye 36, 294-298 (2013).

12. Park, J. H., Song, N. H., Koh, J. W.: Achromobacter xylosoxidans keratitis after contact lens usage. Korean J Ophthalmol 26, 49-53 (2012). 
13. Reddy, A. K., Garg, P., Shah, V., Gopinathan, U.: Clinical, microbiological profile and treatment outcome of ocular infections caused by Achromobacter xylosoxidans. Cornea 28, 1100-1103 (2009).

14. Stepanović, S., Vuković, D., Hola, V., Di Bonaventura, G., Djukić, S., Cirković, I., Ruzicka, F.: Quantification of biofilm microtiter plates: Overview of testing conditions and practical recommendations for assessment of biofilm production by staphylococci. APMIS 115, 891-899 (2007).

15. Kim, M. J., Bancroft, E., Lehnkering, E., Donlan, R. M., Mascola, L.: Alcaligenes xylosoxidans bloodstream infections in outpatient oncology office. Emerg Infect Dis 14, 1046-1052 (2008).

16. Choe, H. S., Son, S. W., Choi, H. A., Kim, H. J., Ahn, S. G., Bang, J. H., Lee, S. J., Lee, J. Y., Cho, Y. H., Lee, S. S.: Analysis of the distribution of bacteria within urinary catheter biofilms using four different molecular techniques. Am J Infect Control 40, 249-254 (2012).

17. Hansen, C. R., Pressler, T., Nielsen, K. G., Jensen, P., Bjarnsholt, T., Høiby, N.: Inflammation in Achromobacter xylosoxidans infected cystic fibrosis patients. J Cyst Fibros 9, 51-58 (2010).

18. Trancassini, M., Iebba, V., Citera, N., Tuccio, V., Magni, A., Varesi, P., De Biase, R. V., Totino, V., Santangelo, F., Gagliardi, A., Schippa, S.: Outbreak of Achromobacter xylosoxidans in an Italian Cystic fibrosis center: Genome variability, biofilm production, antibiotic resistance, and motility in isolated strains. Front Microbiol 5, 138 (2014).

19. Spierer, O., Monsalve, P. F., O'Brien, T. P., Alfonso, E. C., Gologorsky, D., Miller, D.: Clinical features, antibiotic susceptibility profiles, and outcomes of infectious keratitis caused by Achromobacter xylosoxidans. Cornea 35, 626-630 (2016).

20. Lucatelli, J. F., Cantarelli, V. V., Picoli, S. U.: Conjuntivite por Achromobacter xylosoxidans: Relato de caso [Conjunctivitis due to Achromobacter xylosoxidans: Case report]. Arq Bras Oftalmol 72, 261-263 (2009).

21. American Academy of Ophthalmology Cornea/External Disease Panel: Preferred Practice Pattern $^{\circledR}$ Guidelines: Bacterial Keratitis. American Academy of Ophthalmology, San Francisco, CA, USA, 2013, Available at www.aao.org/ppp.

22. Wu, Y. T., Willcox, M., Zhu, H., Stapleton, F.: Contact lens hygiene compliance and lens case contamination: A review. Cont Lens Anterior Eye 38, 307-316 (2015).

23. Chang, J. M., McCanna, D. J., Subbaraman, L. N., Jones, L. W.: Efficacy of antimicrobials against biofilms of Achromobacter and Pseudomonas. Optom Vis Sci 92, 506-513 (2015). 